\title{
Implementation of LTE in Mosul city: problems and solution
}

\author{
Mahmood Samir Sadoon ${ }^{1}$, Saad Ahmed Ayoob ${ }^{2}$ \\ \{mahmoodenp135@student.uomosul.edu.iq ${ }^{1}$, sa_ah_ay@uomosul.edu.iq ${ }^{2}$ \} \\ Electrical Engineering Department, University of Mosul, Mosul, Iraq ${ }^{1,2}$
}

\begin{abstract}
The selection of cell tower locations is an essential step in designing any cellular system network. The sites are selecting according to the specifications of that system. In addition, each cellular system has optimal geographic locations appropriate to the frequency and design of that system. For example, the sites of the second-generation $\left(2^{\text {nd }}\right.$ G) system towers may not be compatible with the sites of the fourth generation $\left(4^{\text {th }} \mathrm{G}\right)$ system towers for long-term evaluations (LTE) technology in terms of design and location. However, most companies that provide cellular service choose the same locations as the $2^{\text {nd }}$ generation towers to prepare $4^{\text {th }}$ generation service to save operating and construction costs. After operating $4^{\text {th }}$ generation service in the same locations of the $2^{\text {nd }}$ generation towers in the city of Mosul, many problems appeared in the cellular coverage. In this paper, these problems are discussing and comparing with the results of the Atoll software. Methods have been proposing to solve these problems and improve cellular coverage by up to $7 \%$ of the area covered.
\end{abstract}

Keywords: LTE, $2^{\text {nd }}$ generation model, $4^{\text {th }}$ generation model, Coverage, Gaps, Atoll.

\section{Introduction}

Cellular communication systems have developed in the past decades and their data speed has increased from the first, second, third, and fourth to fifth generation $(1 \mathrm{G}, 2 \mathrm{G}, 3 \mathrm{G}, 4 \mathrm{G}$, and 5). Fig 1. Shows a comparison between the generations of cellular communication systems in terms of data download speed and the technologies used [1], [2], [3].

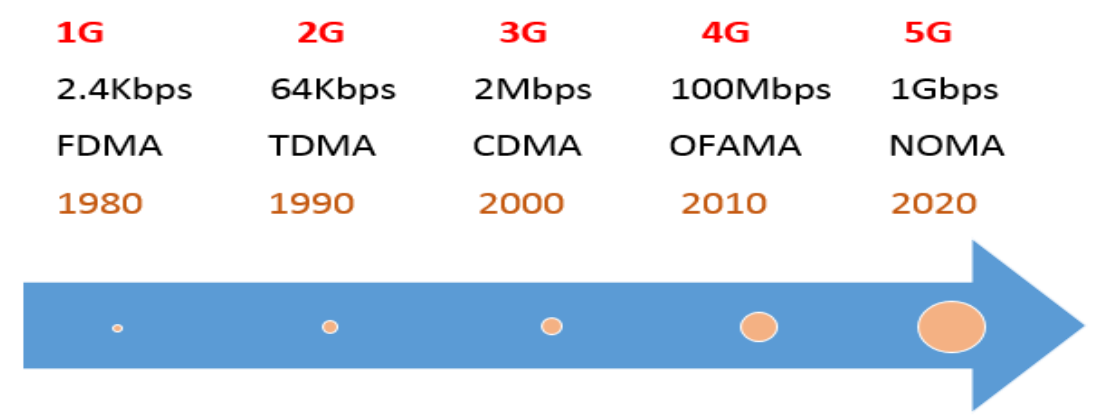

Fig. 1. Technologies used for mobile phone systems and download speed.

With the increasing request of high data transmission rates, $4^{\text {th }}$ generation system with LTE technology have developed, which uses Multi Input Multi Output -Orthogonal Frequency 
Divisions Multiplex (MIMO-OFDM) technology to achieve these requirements as it provides high spectral efficiency with high data rate in multipath [4]. The principle of operation OFDM technology depends on the fragmentation of the signal to be sent into several parts. Each part is sent on a narrow frequency channel called the carrier so that each carrier is orthogonal to the neighbouring carriers on its two ends; for example, when the carrier has the greatest value, the adjacent carriers have a zero value as shown Fig 2. [5], [6].

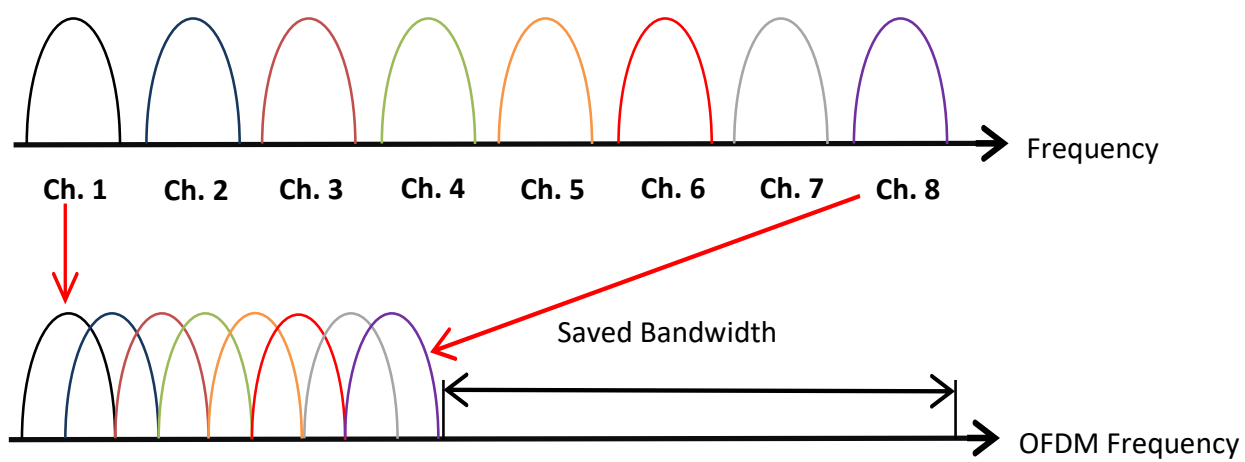

Fig. 2. Orthogonality characteristic of sub-carrier frequencies in OFDM systems.

Although $5^{\text {th }}$ generation technologies have become faster than $4^{\text {th }}$ generation technologies in transmitting data, they are still limited to use due to the high prices of mobile phones that work with this technology [7], and some researchers claim there is a relationship between short frequencies of $5^{\text {th }}$ generation technologies and appearance of the Coronavirus (Covid 19)[ 8]. Other research denied this claim [9], While other studies are still ongoing on this subject, which may restrict the spread of this technology at present time. Research aimed to identify the problems of cellular coverage of mobile phone networks operating with $4^{\text {th }}$ generation -LTE technology in the city of Mosul and to present some practical proposals to solve these problems and improve cellular coverage in the city of Mosul using the Atoll simulation method.

\section{Previous Work}

The central design was used to improve the quality of service for LTE technology for a specific computational area using the Atoll program, where the optimum value of the azimuth angle (-8.7 degrees), mechanical inclination (0 degrees), antenna gain (20 dB) and antenna height (27.5 meters) were achieved. The average signal coverage across the region increased from $-78.56 \mathrm{dBm}$ to $-76.31 \mathrm{dBm}[10]$. Another study discussed the increase in the number of users on the $4 \mathrm{G}$ cellular network in Indonesia. And simulating the deployment of the 4G LTEAdvanced network in Central Jakarta with a frequency spectrum of $2100 \mathrm{MHz}$. The study concluded that the network deployment in Central Jakarta requires at least 109 sites to cover all regions [11]. A new proposal was presented to plan a cellular network working 4G technology using meta-heuristic algorithms and to choose the best locations for the towers by covering the cell with the minimum required power and calculating the average number of users by using Monte-Carlo simulations [12]. 
In a study conducted to design and simulate a cellular system downtown Phnom Penh. LTE system was building with peak data rate and low latency. In addition to determining the dimensions of the coverage areas and the transmitting power of the city of Phnom with it on the map, measuring the signal level and knowing the interference areas [13]. Another study was conducted for a cellular system using $\left(2^{\text {nd }}, 3^{\text {rd, }}\right.$ and $4^{\text {th }}$ generation) technology and measuring the received signal strength at Ondokuz Mayis University (OMU) using the "Netmonitor" application on Android phones. The results showed that the $2^{\text {nd }}$ generation signal is higher than the signal receiving from the $3^{\text {rd }}$ and $4^{\text {th }}$ generation [14]. The growth of subscribers to 2025 for a cellular network (LTE) in Denpasar was predicting using Atoll's Monte Carlo simulation and determination of the maximum subscribers connected to the LTE network at $1800 \mathrm{MHz}$. The simulation results showed that in $2017,99.8 \%$ of subscribers connect successfully and only $0.2 \%$ of users were rejecting while in $2025,99.3 \%$ of users connect successfully and only $0.7 \%$ of users are rejected [15]. A study was conducted to find the best design for a cell operating with LTE technology to improve the quality of communication and coverage in urban areas and rural suburbs and reduce the path loss for the Okumura Hata model for MATLAB by using the Atoll program, where the results were comparing, and the best model was knowing for each region [16].

\section{LTE Architecture}

LTE architectures were designed to increase the data transfer rate, reducing the waiting period, achieving optimal radio access for the data packet, and achieve smoother roaming service and quality, LTE systems consist of radio and non-radio networks, where the radio network called Evolved- UMTS (Universal Mobile Telecommunications Systems) Terrestrial Radio Access Networks (E-UTRAN), While the non-radio part called Evolved Packets Cores (EPC) networks which connect to Packet Data Networks (PDN). Fig 3. shows the architecture of the LTE system with different interfaces for each link [17],[18].
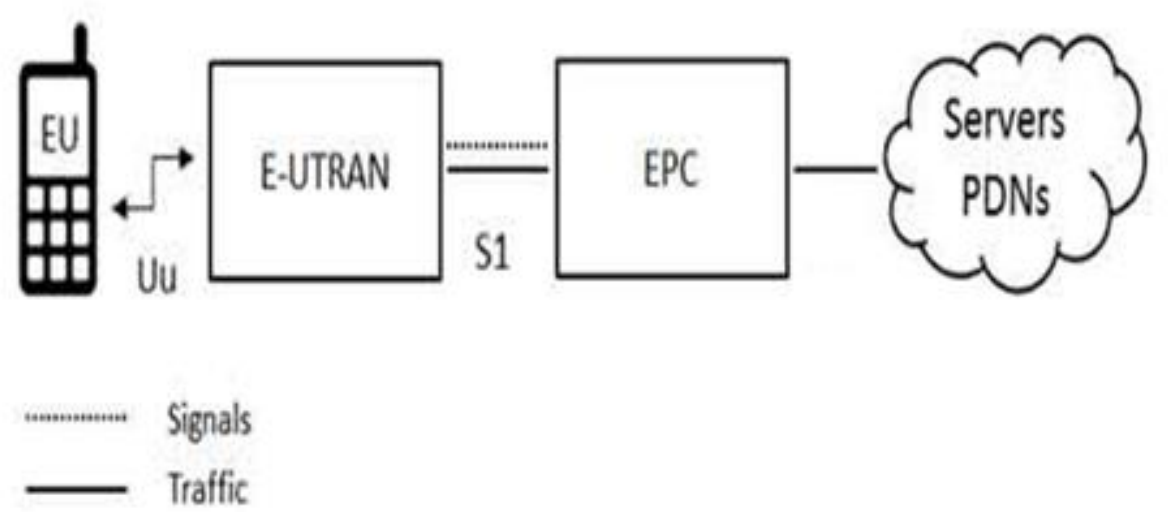

Fig. 3. LTE Architecture. 
The E-UTRAN architecture consists of eNodeB (eNB) which are advanced base stations. These base stations are connecting Equipment users (EU) devices to a network. E-UTRAN is a distributed architecture because it doesn't contain central controllers, Fig 4. is showing that the E-UTRAN architecture consists of a network of advanced base stations that are connecting to other eNB via (x2) link and connects to the core of EPC via the (S1) link, while it is connecting to user's devices via the Uu link. All the following radio functions are operated by (E-UTRAN):

1. Compress the IP packet headers.

2. Data encryption and protection.

3. Connects to EPC networks, which include selecting signals and configuring a path for carrying and routing data.

Radio Resources Management (RRM) includes all functions of radio carriers such as access control, mobile control, user resource allocation, and radio load control. The main function of a radio network is to control the user and establish carriers. It also provides effective and true terminals with (Quality of services QOS), protection, mobility, management, and finally, it allows communication with external IP packet networks [19],[20].

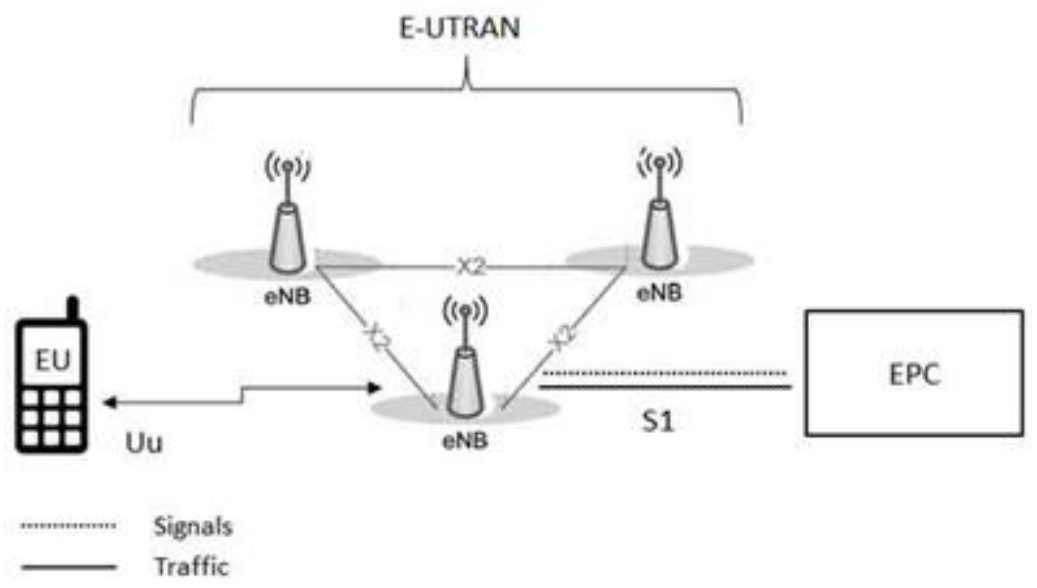

Fig. 4. E-UTRAN Architecture.

Fig 4. shows that the access network is responsible for the cellular coverage through a group of towers (eNB), and each tower covers a certain geographical area in which there are several users' equipment (EU), and the cellular coverage must cover all geographical areas without any coverage gaps between regions (towers) to make all users connect to the cellular network and improves the efficiency and performance of the cellular network.

\section{Simulation Model for LTE 4th Generation}

With the development and spread of cellular networks, many simulation programs have appeared to represent these networks, Atoll is one of these programs that is using to simulate cellular networks. In this model, a cellular communication network used both $2^{\text {nd }}$ generation and $4^{\text {th }}$ generation with LTE technologies was simulated in the city of Mosul. Six sites for one of the companies operating in the city were selecting, represented, and simulated in the Atoll 
program, and their properties were studying to find out the reasons for the poor cellular coverage of the $4^{\text {th }} \mathrm{G}$ network in the city.

\subsection{Assumptions}

The $2^{\text {nd }} \mathrm{G}$ model and the $4^{\text {th }}$ generation model depended on some assumptions:

1. The frequency of the $2^{\text {nd }}$ generation is 900 megahertz $(\mathrm{MHz})$.

2. The frequency of the $4^{\text {th }}$ generation is $1800 \mathrm{MHz}$

3. Six towers (sites) for the $2^{\text {nd }}$ generation model.

4. Six towers for the $4^{\text {th }}$ generation model.

5. Each tower consists of three cells (three sectors).

6. The coordinates and locations of the towers are identical to the real coordinates of the towers of a company operating in the city.

7. The characteristics of the tower in the simulation programs for height, direction, antenna tilt, and transmitting power are like the real characteristics of the tower.

\subsection{Variables}

The variables that we are using for the $2^{\text {nd }}$ generation and $4^{\text {th }}$ generation models are showing in Table 1 . Note that the transmitting power used is $43 \mathrm{dBm}$ and the antenna tilt angle is 0 degrees.

Table 1. Coordinates and site properties for simulation models.

\begin{tabular}{ccccccccc}
\hline Site & longitude & Latitude & $\begin{array}{c}\text { Antenna } \\
\text { high for } \\
\text { sector 1 }\end{array}$ & $\begin{array}{c}\text { Antenna } \\
\text { high for } \\
\text { sector 2 }\end{array}$ & $\begin{array}{c}\text { Antenna } \\
\text { high for } \\
\text { sector 3 }\end{array}$ & $\begin{array}{c}\text { Antenna } \\
\text { azimuth } \\
\text { sector 1 }\end{array}$ & $\begin{array}{c}\text { Antenna } \\
\text { azimuth } \\
\text { sector 2 }\end{array}$ & $\begin{array}{c}\text { Antenna } \\
\text { azimuth } \\
\text { sector 3 }\end{array}$ \\
\hline Zuhor & 43.1923 & 36.3754 & 18 & 16 & 18 & 0 & 120 & 240 \\
Zuho1 & 43.1978 & 36.3759 & 19 & 19 & 19 & 0 & 120 & 240 \\
Zuho2 & 43.2026 & 36.3777 & 18 & 18 & 16 & 0 & 120 & 240 \\
Zuho3 & 43.195 & 36.3825 & 16 & 18 & 16 & 0 & 120 & 240 \\
Zuho4 & 43.2026 & 36.3822 & 18 & 18 & 18 & 0 & 120 & 240 \\
Zuho5 & 43.1963 & 36.3885 & 22 & 22 & 22 & 0 & 120 & 240 \\
\hline
\end{tabular}

\section{Simulation and Results}

The level of a signal receiving in a cellular system considers one of the characteristics of system efficiency, and the efficient system has a better signal level. To test the efficiency of cellular networks in the city of Mosul, a simulation of $2^{\text {nd }}$ and $4^{\text {th }}$ generation's networks were madding for a group of towers, for one of the provided service cellular networks in the city. According to the assumptions that were mentioning previously and using the Atoll, program at 
greater than $-70 \mathrm{dbm}$ receiving signal. The level of a signal receiving for the $2^{\text {nd }}$ generation shows in Fig 5. While the level of the received signal for the $4^{\text {th }}$ generation is showing in Fig 6.

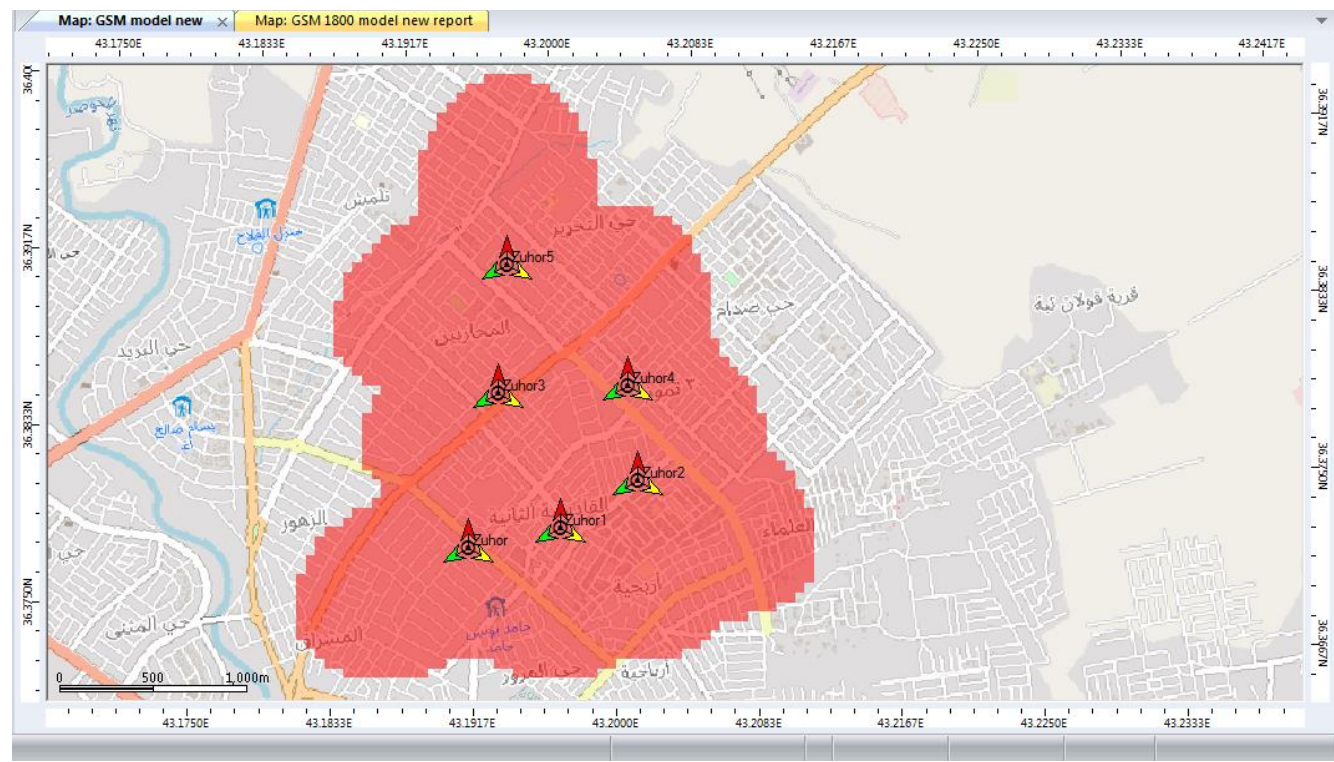

Fig. 5. The level of the received signal for the $2^{\text {nd }}$ generation.

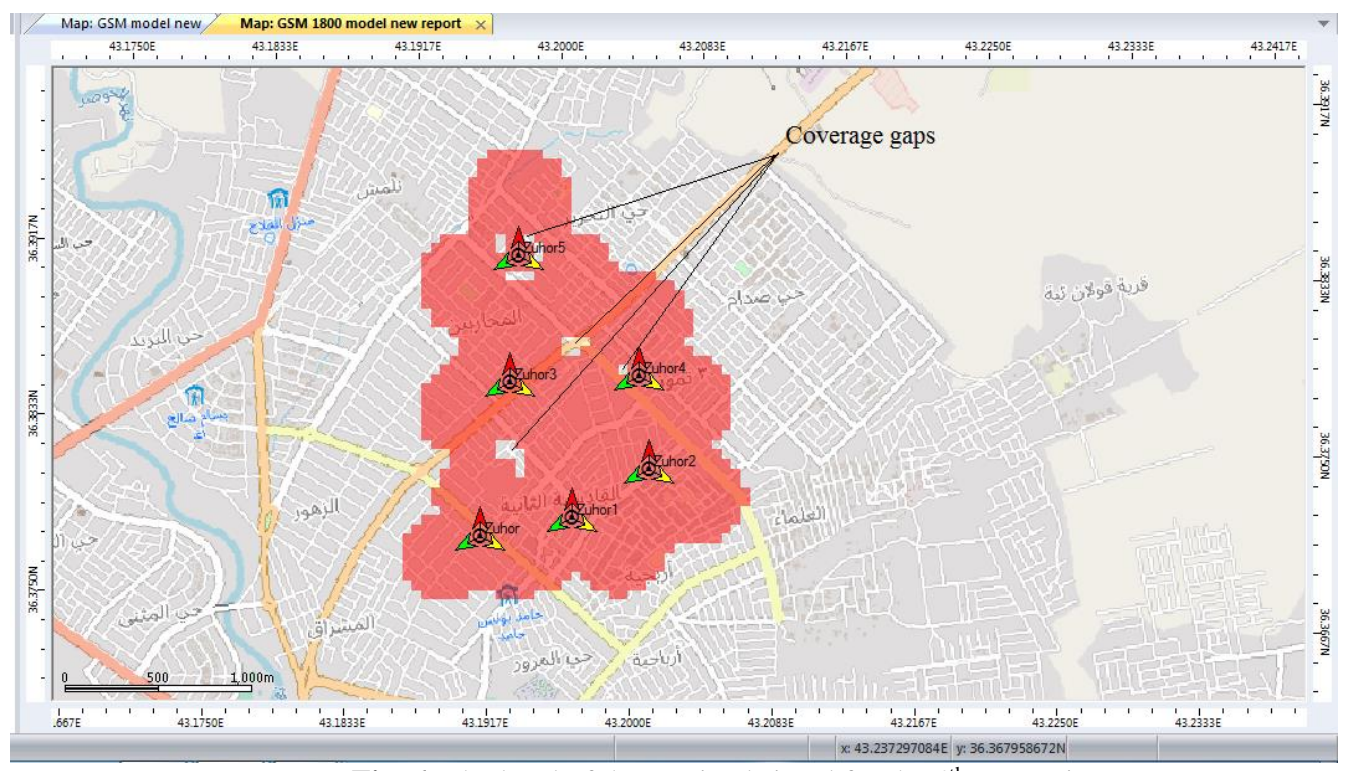

Fig. 6. The level of the received signal for the $4^{\text {th }}$ generation.

The red colour in Figs 5 and 6 . Are showing the areas covered by the cellular network consisting of six towers distributed on the geographical map of an area in Mosul city using the simulation 
program Atoll, in Figure 6. which represents the signal level for the $4^{\text {th }}$ generation were near areas from towers but without coverage (gaps), and that means several users, despite their proximity to the towers, but they have poor cellular service, while the same areas in Figure 5. Are completely covering by the signal because it works with the technology of the $2^{\text {nd }}$ generation, whose frequency is less than the frequency of the $4^{\text {th }}$ generation therefore the coverage of the $2^{\text {nd }}$ generation is higher than the coverage of the $4^{\text {th }}$ generation. The companies that provided cellular service in the city of Mosul have used the same sites of the $2^{\text {nd }}$ generation towers to prepare the $4^{\text {th }}$ generation service to save the cost, but this procedure led to the existence of problems and gaps coverage for the $4^{\text {th }}$ generation. To solve coverage problems and fill the gaps, there are a set of proposals that we can show:

1. Change some of the towers' locations

2. Increase antenna height

3. Change tilt of the transmitter antenna

4. Change azimuth of the transmitter antenna

Each proposal has characteristics that depend on the structure of cellular systems and the nature of the geographical areas that the network operates. Mosul city has population density and urban nature and closed area so that most of the communication towers are building with few heights above the rooftops. To increase the height of the antennas, we need to change the structure of the tower, and this proposal does not proportionate with the nature of the small areas of the rooftops in the city, so the proposal to change antenna height cannot be used in all areas of the city. As for the proposal to change the azimuth antenna should not be used in urban areas that suffer from poor coverage in most directions because it increases coverage in one direction and decreases it in the other. The proposal to change some tower locations for the cellular network in the city of Mosul, despite its cost, but it the best choice to cover areas and fill coverage gaps. As will proposal for change antenna tilt can also be used to increase coverage in nearby areas, if it does not have a significant impact on coverage of distant areas. It is also possible to take the proposal to change some sites and the proposal to change the antenna tilt to obtain the best cellular coverage and at a low cost.

By using the proposal to change antennas tilt with the proposal to change some tower's location for a simulation model of 4th generation network, the coordinates of two sites (Zuhor and Zuhor4) of the six tower sites were changed and change antennas tilt in one tower (Zuhor5) only, as shown in Table 2.

Table 2. Changing the coordinates and antennas tilt for some sites for simulation models.

\begin{tabular}{cccccc}
\hline Site & longitude & Latitude & $\begin{array}{c}\text { Antenna Tilt } \\
\text { for sector 1 }\end{array}$ & $\begin{array}{c}\text { Antenna Tilt } \\
\text { for sector 2 }\end{array}$ & $\begin{array}{c}\text { Antenna Tilt } \\
\text { for sector 3 }\end{array}$ \\
\hline Zuhor & 43.1911441 & 36.3791889 & same & same & same \\
Zuhor4 & 43.2026371 & 36.3839493 & same & same & same \\
Zuho5 & same & same & add 4 degree & add 4 degree & add 4 degree \\
\hline
\end{tabular}


After using the suggestions in Table 2. For the simulation model, the level of the received cellular signal was increasing for the $4^{\text {th }}$ generation, coverage gaps are filling in the $4^{\text {th }}$ generation model, and both second and fourth generation areas became completely covered by cellular coverage, as showing in Figs 7 and 8.

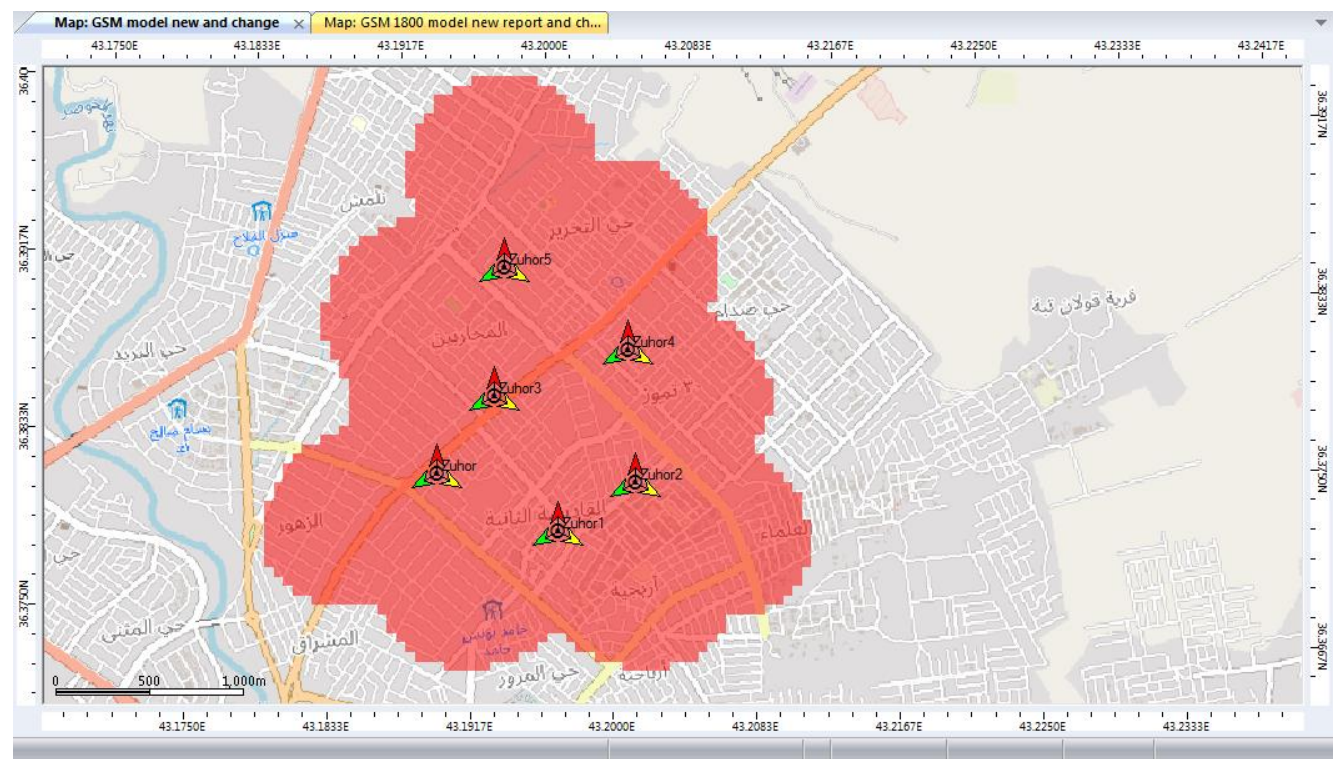

Fig. 7. Received signal levels for $2^{\text {nd }}$ generation.

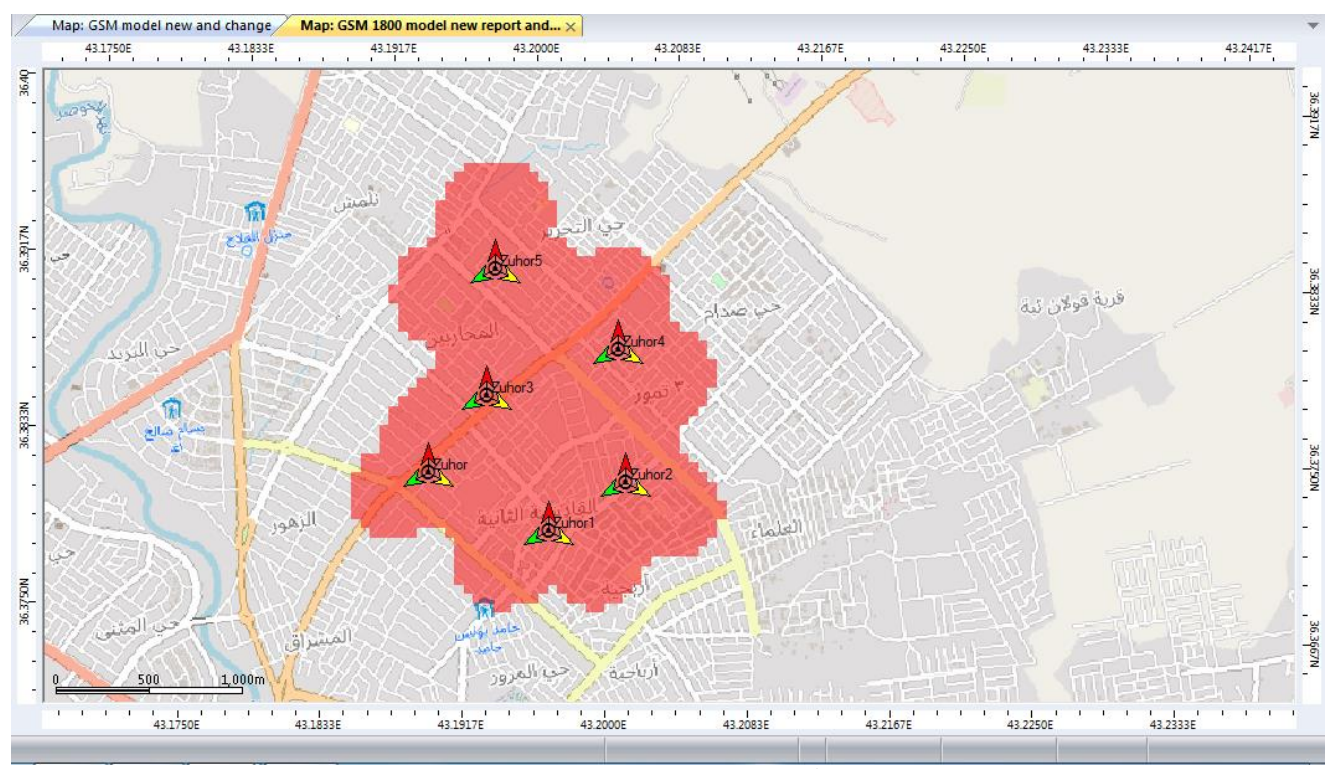

Fig. 8. Received signal levels for $4^{\text {th }}$ generation. 
Figs 7 and 8. Show the improvement in coverage. Therefore, the total coverage areas increased in addition to closing coverage gaps. In the $4^{\text {th }}$ generation model, a total covered area by a cellular signal of the smaller signal level $-70 \mathrm{dbm}$ increased from 2.93 square kilometres to 3.14 square kilometres, as shown in Fig 9 and 10.

$\mathrm{km}^{2}$

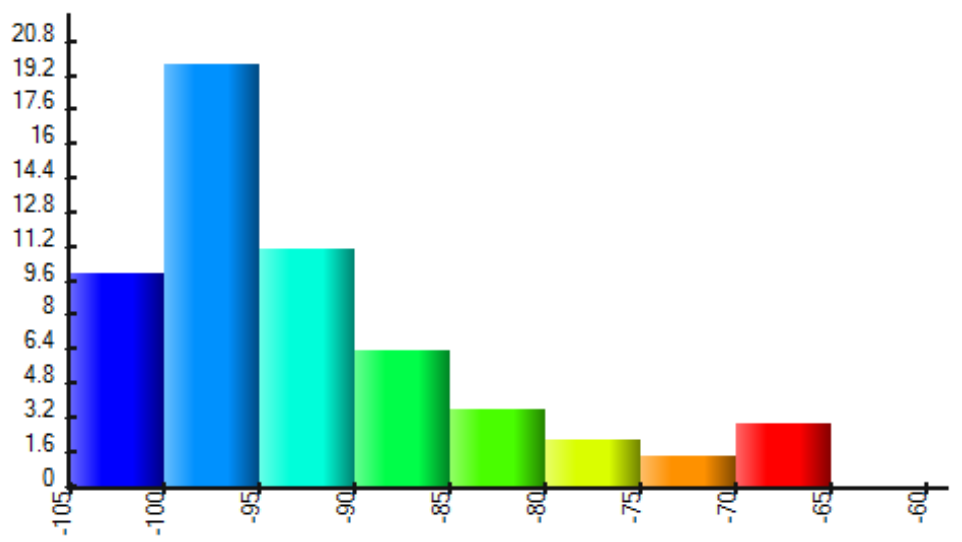

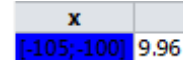

$[-100 ;-95] \quad 19.7$ $[-95 ;-90] \quad 11.08$ $[-90 ;-85] \quad 6.31$ $[-85 ;-80] \quad 3.53$ $[-80 ;-75] \quad 2.15$ $[-75 ;-70] \quad 1.4$

Best Signal Level (dBm)

Fig. 9. Covered areas for $4^{\text {th }}$ generation technology before change towers location and antennas tilt.

$\mathrm{km}^{2}$

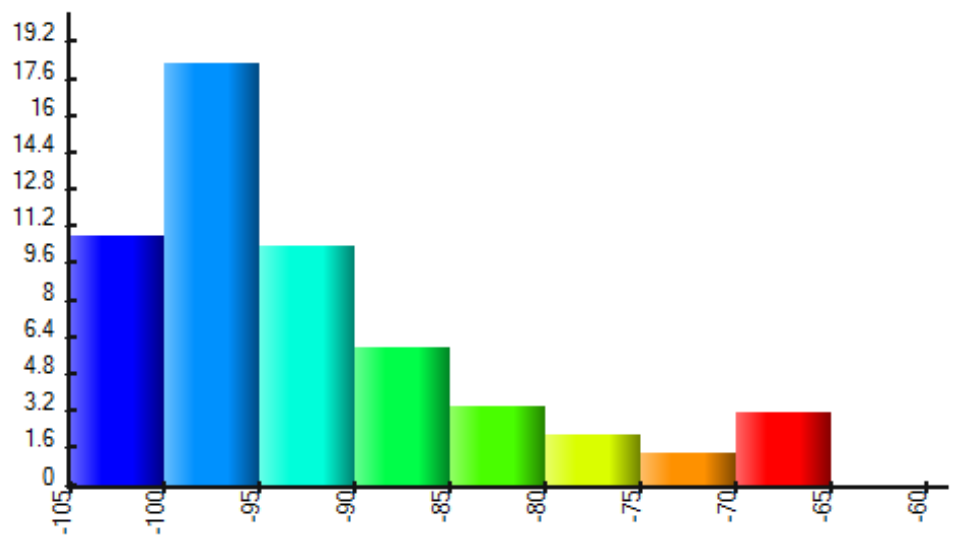

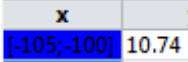

$[-100 ;-95] \quad 18.24$ $[-95 ;-90] \quad 10.33$ $[-90 ;-85] \quad 5.94$ $[-85 ;-80] \quad 3.43$ $[-80 ;-75] \quad 2.13$ $[-75 ;-70] \quad 1.35$

Best Signal Level (dBm)

Fig. 10. Covered areas for $4^{\text {th }}$ generation technology after change tower's location and antennas tilt.

Figs 9 and 10. Are showing the levels of a received signal for each area in a square kilometre, where the additional covered areas by a signal level greater than $-70 \mathrm{dbm}$ are $0.21 \mathrm{Km}^{2}$, which is equivalent to an increase of $7 \%$ of the total coverage area, in addition, other levels of the 
signal coverage decreased, and that reduces the interference and handoff process (hand over). Increasing coverage area, closing the gaps, and reducing interference come after using proposal of change positions of some towers and change of antennas tilt for $4^{\text {th }}$ generation simulation model.

\section{Comparison with Previous Works}

Most of the previous works dealt with the topics of designing virtual cellular networks using the fourth-generation technology for choosing the optimal values for these networks in terms of tower locations, transmitted power, capacity, number of users, and traffic density. while in this study, real problems were referred to in a cellular fourth-generation network operating in Mosul city as will proposals to solve those problems and improve cellular coverage in the city were referred in the study.

\section{Conclusions}

A simulation model of 4th generation system was built which consisting of a group of tower sites for one of the cellular service companies in Mosul city. The 4th generation system services were adding to the same sites (coordinates) of the 2 nd generation system, and each site became equipped with both the 4 th generation and 2 nd generation services. The simulation model showed that there are gaps in the cellular signal received greater than $-70 \mathrm{dBm}$ for the 4th generation, which has a higher frequency than the 2nd generation, and that affects the efficiency of cellular service. In this study, a set of proposals were presented to close the coverage gaps and improve cellular coverage by up to $7 \%$ of the area covered for the 4 th generation cellular service. A proposal to change some tower locations and a proposal to change antenna tilt was chosen as the best suggestions, where it compact with the geographical nature of Mosul city and the nature of the structure of the cellular network. our future work will be to make Drive Test (DT) during a call for the cellular networks that provide cellular services in the city of Mosul and roaming between the locations of the cell towers to improve the 4 th generation service in the city.

\section{Acknowledgment}

This work was supported by Electrical Department, Engineering College, Mosul University

\section{References}

[1] Vora L J. EVOLUTION OF MOBILE GENERATION TECHNOLOGY: 1G TO 5G AND REVIEW OF UPCOMING WIRELESS TECHNOLOGY 5G. IJMTER. 2015. Volume 02(Issue 10): page 281290.

[2] C S Patil, R R Karhe, M A Aher. Development of Mobile Technology: A Survey. IJAREEIE. November 2012. Volume 1(issue 5).page 374 -379.

[3] Gawas A U. An Overview on Evolution of Mobile Wireless Communication Networks:1G-6G. IJRITCC. May 2015. Volume 3(Issue 5). Page 3130- 3133

[4] Venkateswarlu P, Nagendra R. "Channel Estimation Techniques in MIMO-OFDM LTE Systems. IJERA. July 2014. Volume 4(Issue 7). Page 157-161. 
[5] Agarwal A, Agarwal K. Implementation and Performance Evaluation of OFDM System in Diverse Transmission Channel Using Simulink. AJEEE. 2015. Volume 3. Page 117-123.

[6] Dixit S, Katiyar H. Performance of OFDM in time selective Multipath fading channel in 4G Systems. Fifth International Conference on Communication Systems and Network Technologies. 2015. Page 421-424.

[7] Bega D, Gramaglia M, Bernardos C J, Banchs A, Costa-Perez X. Towards the network of the future: from enabling technologies to $5 \mathrm{G}$ concepts. Transaction on Emerging telecommunication technologies. August 2017. Volume 28(Issue8).Page 1-13.

[8] Fioranelli M, Sepehri A, Roccia M G, Jafferany M, Olisova O Yu, Lomonosov K M, Lotti T. 5G Technology and induction of coronavirus in skin cells. Journal of biological regulators and homeostatic agents.2020. Volume 34. Page 3-10

[9] Uthman M, Shaibu F E, Najashi B G, Labran I F, Sadiq A. 5G Radiation and COVID-19: The NonExistent Connection. IJRECE. June 2020. Vol 8(Issue 2). Page 34-38.

[10] Amit Bhagat and Nanda Bikram Adhikari, "Optimization of QoS key parameters in LTE network by using central composite design (CCD)", Research Journal of Engineering Sciences, Vol. 10(1), January 2021.

[11] P. A. Fadhila and M. I. Nashiruddin, "Planning \& Simulation Analysis of 4G LTE-Advanced Mobile Network Deployment Using 2100 MHz Frequency Spectrum in Dense Urban Area: Case Study in Central Jakarta," 2021 IEEE Asia Pacific Conference on Wireless and Mobile (APWiMob), 2021, pp. 8-14.

[12] Ghazzai H, Yaacoub E, Alouini M-S, Dawy Z, Adnan A-D. Optimized LTE Cell Planning with Varying Spatial and Temporal User Densities. IEEE. 2015.

[13] Seven S, Astuti R P, Prasetya B.Design and Simulation of LTE Radio System for Broadband Wireless Access in Central Phnom Penh. e-Proceeding of Engineering. 2015. Volume 2. Page 3884-3889.

[14] Engiz B K, Kurnaz Ç. Comparison of Signal Strengths of 2G/3G/4G Services on a University Campus. IJAMEC. 2016. Page 37-42.

[15] Rahmatia S, Azzahra A A, Ismail M, Astharini D, Samijayani O N. Subscriber Growth Forecasting of LTE Network $1800 \mathrm{MHz}$ FDD at Denpasar City using Monte Carlo Simulation. JET. 2019. Volume 19.

[16] Maswood M M S, Dey U K, Uddin Md A, Ghosh A K, Mamun Md M, Sonia S S, Alharbi A G . A Novel Approach to Design the Cell of LTE Cellular Network to Improve the Call Quality and Coverage Area in Rural and Suburban Area. IEEE. 2021.

[17] Dahlman E, Parkvall S, Sköld J. 4G LTE/LTE-Advanced for Mobile Broadband. UK: Academic Press is an imprint of Elsevier; 2011. Page 109,110.

[18] Holma H, Toskala A. LTE-ADVANCED. Finland: Nokia Siemens Networks; 2012. Page 22, 23.

[19] Dima Dababneh, B.SC.,"LTE Traffic Generation and Evolved Packet Core (EPC) Network Planning", Ottawa-Carleton Institute for Electrical and Computer Engineering (OCIECE) Department of Systems and Computer Engineering Carleton University Ottawa, Ontario, Canada, March 2013.

[20] Alexander Kukushkin, "4G- Long Term Evolution (LTE) System," in Introduction to Mobile Network Engineering: GSM, 3G-WCDMA, LTE and the Road to 5G, Wiley, pp.205-291, 2018. 